\title{
Simulation of Applique Designs Using Cad
}

\author{
Ansul Sharma ${ }^{1}$, Saroj S. J Singh ${ }^{2}$, Neelam M Rose ${ }^{1}$ and Shefali Massey ${ }^{3}$ \\ Department of Clothing \& Textiles, College of Home Science, CCS University, \\ Hisar, Haryana, India \\ Department of Clothing \& Textiles, College of Home Science, CCS University, \\ Hisar, Haryana, India \\ Department of Clothing \& Textiles, College of Home Science, \\ GBPUAT, Pantnagar, India \\ *Corresponding author
}

\section{A B S T R A C T}

\section{Keywords}

Computer aided designing, simulation, applique, digital printing, designing, motifs

Article Info

Accepted:

15 January 2020

Available Online:

10 February 2020
Creative designing is the process where the designer plays with the arrangement of lines, forms and colours to provide beauty to the end product. The conventional method of designing is tedious, time consuming and laborious. The modern technique aims at simulation of conceived designing onto monitor which helps in better visualization with wide spectrum of designs. The possibilities of designing with respect to speed, pattern creation, editing, repeating, flexibility, variety, colour ways and cost effectiveness are endless with the introduction of CAD. The designs or motifs from Indian traditional crafts can easily be adapted for designing textiles with the help of computer aided designing. The simulation of traditional designs further into textile products can be a way to preserve the Indian cultural heritage as well as an innovative mode of showcasing the uniqueness of Indian art work. Therefore, this study is an attempt to develop a new line of designs of appliqué motifs. The traditional 1000 appliqué motifs were collected and on the basis of their suitability for developing designs for digital printing technique, 110 motifs were screened. The preferential index was developed for 110 motifs and twenty motifs were selected. The selected twenty motifs were simulated with the help of various computer software tools for enlargement/reduction of size, transformation, modification, rotation, editing until an aesthetically appealing and required arrangement of motifs was obtained for creation of innovative contemporary designs for textile products. Thirty seven new designs were developed using selected twenty motifs and finally top five preferred designs were selected.

\section{Introduction}

Designing is a process to compose a unified whole in order to satisfy a particular purpose by using the basic elements of the visual arts such as line, form, space, light, colour, transparency, motion and texture. Textile designing is the most demanding and emerging field as it is full of scope and creativity. The innovative designs can be created from a variety of sources like Indian folk art and crafts, nature, temples, printing, 
sculptures, carvings etc. There is a great variety of styles showing the creative ability of the artisans to adapt the designs according to new market needs. The processes evolved from time immemorial have remained the same $(15,18)$ India had always been known as the land that portrayed cultural and traditional vibrancy through its conventional arts and crafts. The motifs and patterns of any art are indicative of the rich cultural heritage that the artisans have been following since antiquity (1).

Appliqué is one of the ancient Indian craft in which the decorative effect is obtained by superposing patches of coloured fabrics on a base fabric, edges of the patches being sewn into some form of stitchery. The rich motifs and designs of these existing art and craft can be readily adapted into contemporary forms to make them suitable for various textile products as per latest fashion trends. Mass production and digitalization have given consumers a yearning for hand-crafted products with heritage, causing designers to reimaging its tradition and authenticity. The drawback of appliqué work is that it is very time consuming but with the advancement of technology, the traditional art can be revived using computer and digital machines to make intricate designs on the fabric using suitable software in short duration (11).

In today's fast changing world of fashion and textile designing designers and manufacturers are standing on a threshold where something new and different is always welcome to suit the rapidly growing fashion consciousness in the market that exerts a great pressure on them. Designers make use of practical knowledge and creative abilities to develop or modify an abstract idea into formal design for the product. In the field of textiles, digital textile printing is considered to be the next generation printing technology that consists of printing design on fabric directly from computer using specialized digital technology. Digital technology is an excellent reflection of original artwork with a right blend of classic and elegant view. It defines a set of technologies that could be used to transfer a design in the digital form on the target surface (7).

Consumers demands for value addition, diversified products, technology refinement and innovation in textile and apparel articles. To survive in the global market, one has to keep in pace with the adventure of modern generations which demands for flexible, dynamic and versatile technique aims at simulation of conceived designing onto the monitor which helps in better visualization of a wide spectrum of textile designs (3). So an attempt was made to overcome the limitations of appliqué work by using digital printing for textile products. The purpose of this research work was to make an attempt to revive the traditional appliqué work through digital technology. Therefore, the study was planned with the following objectives, To create textile designs from motifs of traditional appliqué work for saris. And to transform and simulate the selected designs into digital form.

\section{Materials and Methods}

\section{Collection of motifs}

The traditional Indian applique motifs were collected for the present study. The various primary and secondary sources i.e. books, journals, encyclopaedia and websites were explored and museums, art galleries, fairs etc. were visited. A total of 1000 collected motifs were critically analysed by researcher and advisor. On the basis of their suitability for developing designs of appliqué work for digital printing, 110 motifs were screened. These screened motifs were sketched manually as well as were again created and 
refined on computer using Corel DRAW and Adobe Photoshop software to get the required intricacy and fineness.

\section{Selection of motifs}

In order to know preferences of experts regarding 110 screened motifs, preferential choice index was developed. In this, the collected motifs were got assessed and ranked according to the panel of thirty expert's preference .Mean scores were calculated for all the motifs according to preferences obtained and ranks were assigned. Twenty top preferred motifs were selected to develop designs.

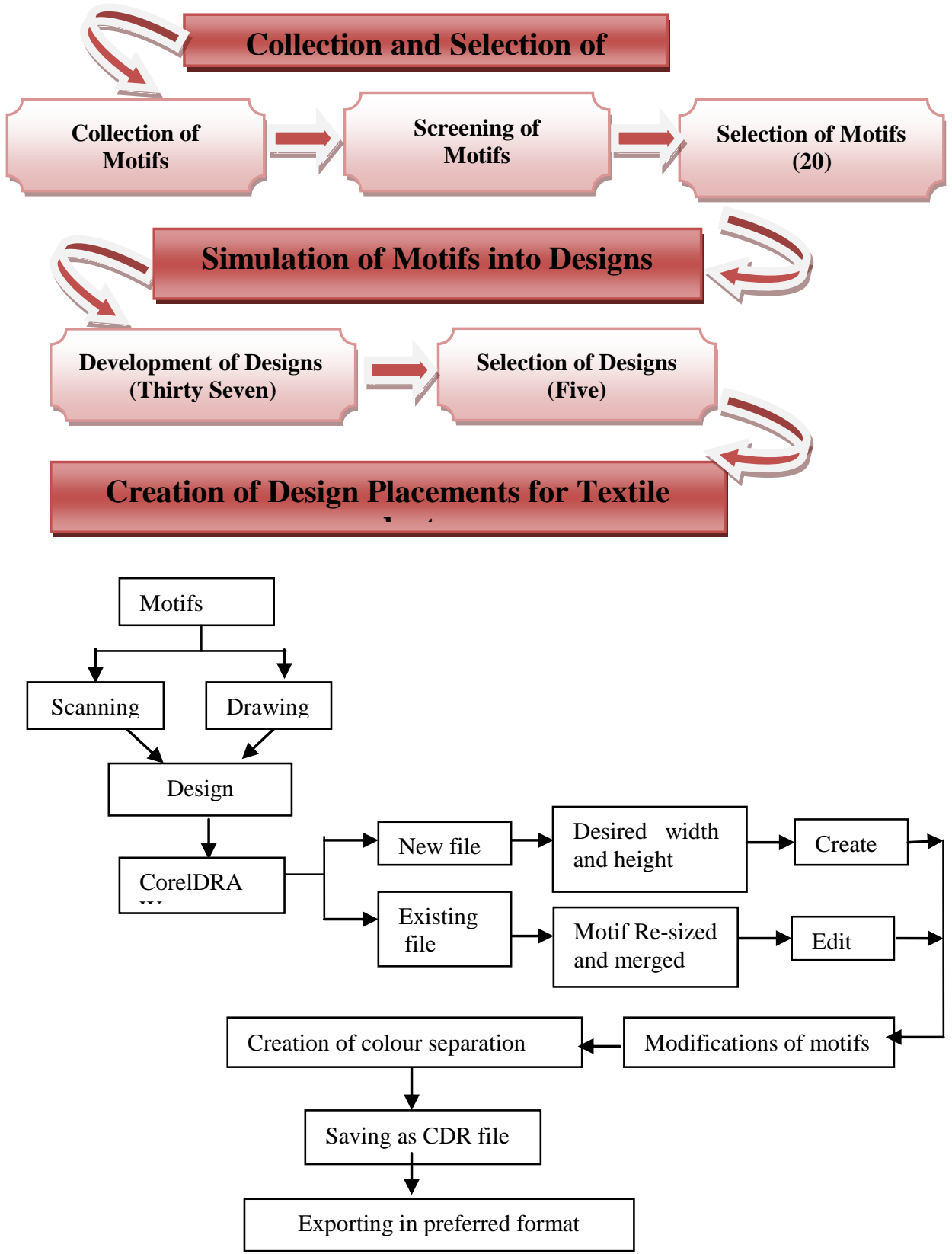

Fig.1 Process flow of digitization of motifs using CAD software Corel DRAW 
Plate.1 Screened Motifs of Appliqué

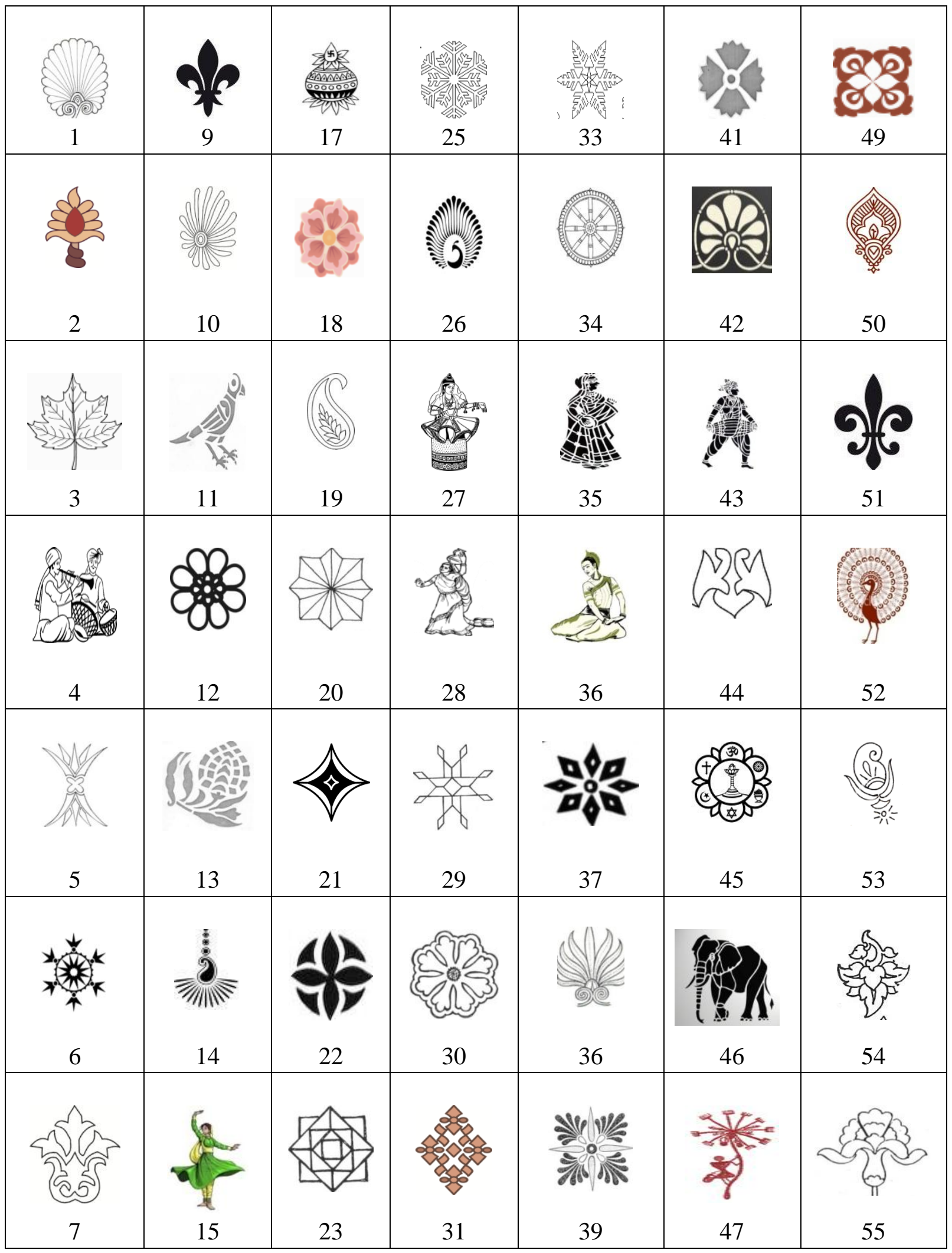




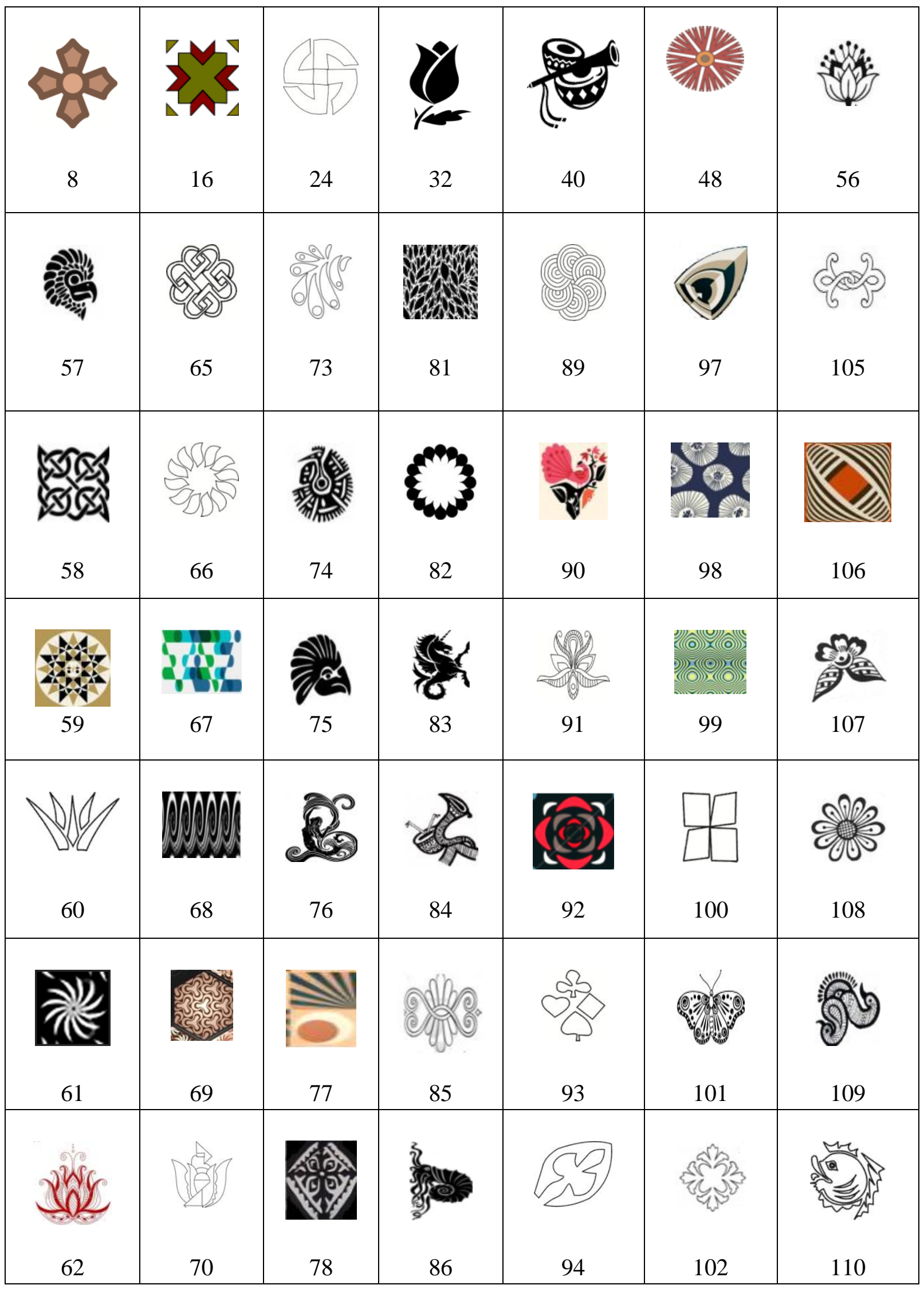




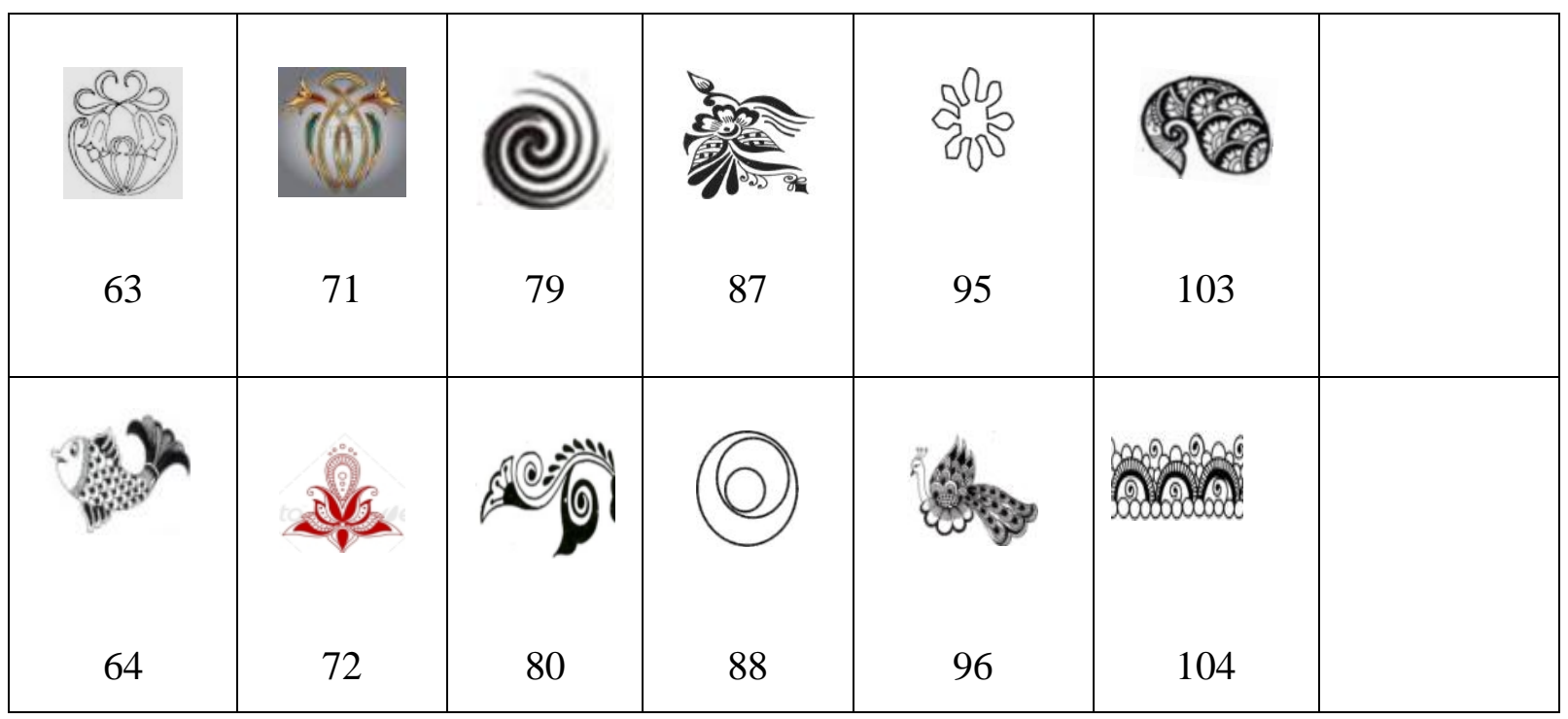

Plate.1 Screened Motifs of Appliqué

\section{Simulation of Motifs into Designs}

\section{Design development}

The selected twenty motifs were simulated for creation of innovative contemporary designs for saris. Keeping in mind the principles of art, the designs were created from the selected twenty motifs. The simulation of motifs was done with the help of Corel DRAW using various software tools for enlargement/ reduction of size, transformation, modification, rotation, editing until an aesthetically appealing and required arrangement of motifs was obtained.

A total of thirty seven designs were developed using only one or components of two to four motifs. The process flow of digitization of motifs using CAD software is shown in fig 1 .

\section{Selection of designs}

To know the preferences of experts regarding created designs of appliqué, preferential choice index was developed. All created thirty seven designs were evaluated by the experts for selection of top preferred designs for application on textile garments.
All the designs were ranked according to their preferences obtained and top preferred five designs were selected for further work.

\section{Results and Discussion}

\section{Collection of motifs}

India has rich and varied textile heritage where traditional motifs of each art and craft serves as a rich source of textile designing. The traditional motifs can be innovatively used to generate creative new designs for textile products.

As per inspiration from appliqué, 1000 traditional motifs were collected from primary and secondary sources. The screened 110 motifs considered suitable for saris are presented in Plate -1 .

\section{Selection of motifs}

This includes preferences of experts for screened motifs for design development. All the screened motifs were got evaluated from a panel of thirty experts and the results obtained are presented in Table 1 
Table.1 Preferential choices of motifs for design development $n=30$

\begin{tabular}{|c|c|c|c|c|c|c|c|c|}
\hline $\begin{array}{c}\text { Motifs } \\
\text { No. }\end{array}$ & $\begin{array}{l}\text { Mean } \\
\text { scores }\end{array}$ & Ranks & $\begin{array}{c}\text { Motifs } \\
\text { No. }\end{array}$ & $\begin{array}{l}\text { Mean } \\
\text { scores }\end{array}$ & Ranks & $\begin{array}{c}\text { Motifs } \\
\text { No. }\end{array}$ & $\begin{array}{l}\text { Mean } \\
\text { scores }\end{array}$ & Ranks \\
\hline 1 & 49.36 & LXIX & 38 & 44.60 & LXXXI & 75 & 27.40 & CVII \\
\hline 2 & 51.03 & LXI & 39 & 38.86 & XCVI & 76 & 42.80 & LXXXV \\
\hline 3 & 53.06 & LV & 40 & 27.20 & CVIII & 77 & 52.70 & LVI \\
\hline 4 & 56.10 & XLVIII & 41 & 42.66 & LXXXVIII & 78 & 59.30 & XLI \\
\hline 5 & 60.70 & XXXVI & 42 & 44.93 & LXXIX & 79 & 55.00 & L \\
\hline 6 & 46.80 & LXXV & 43 & 54.13 & LI & 80 & 49.70 & LXVIII \\
\hline 7 & 67.00 & XX & 44 & 68.06 & XIX & 81 & 57.70 & XLV \\
\hline 8 & 42.60 & LXXXVII & 45 & 50.33 & LXVI & 82 & 63.90 & XXIX \\
\hline 9 & 47.90 & LXXIV & 46 & 42.30 & LXXXIX & 83 & 65.00 & XXIV \\
\hline 10 & 72.70 & XIV & 47 & 42.70 & LXXXVI & 84 & 31.60 & CVI \\
\hline 11 & 48.60 & LXXII & 48 & 50.60 & LXIII & 85 & 64.80 & XXVI \\
\hline 12 & 78.00 & VIII & 49 & 45.90 & LXXVII & 86 & 39.30 & XCV \\
\hline 13 & 52.47 & LVII & 50 & 44.80 & LXXX & 87 & 4.030 & XCIV \\
\hline 14 & 43.90 & LXXXIII & 51 & 65.60 & XXII & 88 & 72.30 & XV \\
\hline 15 & 44.56 & LXXXII & 52 & 42.06 & $\mathrm{XC}$ & 89 & 85.80 & II \\
\hline 16 & 43.03 & LXXXIV & 53 & 53.90 & LII & 90 & 51.30 & LX \\
\hline 17 & 51.56 & LVIII & 54 & 40.06 & XCIII & 91 & 74.60 & XI \\
\hline 18 & 46.70 & LXXVI & 55 & 48.76 & LXX & 92 & 60.40 & XXXVIII \\
\hline 19 & 73.50 & XII & 56 & 59.40 & XL & 93 & 79.00 & VI \\
\hline 20 & 38.83 & XCVII & 57 & 50.06 & LXVII & 94 & 73.30 & XIII \\
\hline 21 & 25.80 & CIX & 58 & 64.90 & XXV & 95 & 77.90 & IX \\
\hline 22 & 36.80 & C & 59 & 57.43 & XLVI & 96 & 63.40 & XXXI \\
\hline 23 & 48.70 & LXXI & 60 & 70.26 & XVI & 97 & 86.50 & I \\
\hline 24 & 68.10 & XVIII & 61 & 64.30 & XXVIII & 98 & 61.00 & XXXV \\
\hline 25 & 33.90 & $\mathrm{CV}$ & 62 & 65.40 & XXIII & 99 & 50.40 & LXV \\
\hline 26 & 19.36 & $\mathrm{CX}$ & 63 & 50.50 & LXIV & 100 & 69.23 & XVII \\
\hline 27 & 34.50 & CIV & 64 & 63.13 & XXXIII & 101 & 59.20 & XLII \\
\hline 28 & 34.70 & CIII & 65 & 78.30 & VII & 102 & 53.20 & LIV \\
\hline 29 & 63.60 & XXX & 66 & 84.40 & III & 103 & 60.40 & XXXIX \\
\hline 30 & 48.50 & LXXIII & 67 & 60.60 & XXXVII & 104 & 50.63 & LXII \\
\hline 31 & 40.46 & XCII & 68 & 58.50 & XLIII & 105 & 64.40 & XXVII \\
\hline 32 & 37.40 & XCIX & 69 & 35.20 & CII & 106 & 63.20 & XXXII \\
\hline 33 & 62.03 & XXXIV & 70 & 79.60 & $\mathbf{V}$ & 107 & 57.80 & XLIV \\
\hline 34 & 45.80 & LXXVIII & 71 & 66.30 & XXI & 108 & 53.60 & LIII \\
\hline 35 & 37.93 & XCVIII & 72 & 35.86 & CI & 109 & 51.50 & LIX \\
\hline 36 & 40.76 & XCI & 73 & 80.10 & IV & 110 & 74.90 & $\mathbf{X}$ \\
\hline 37 & 57.20 & XLVII & 74 & 55.20 & XLIX & & & \\
\hline
\end{tabular}


The data presented in Table 1 reveal that as per experts' preferences, motif number 97 scored highest mean score 86.50 and ranked I followed by motif number $89(85.80)$ ranked II, 66(84.40) ranked III, 73(80.10) ranked IV, 70(79.60) ranked $\mathrm{V}, 93(79.00)$ ranked VI, 65(78.30) ranked VII, 12(78.00) ranked VIII, 95(77.90) ranked IX and motif number 110(74.90) got X rank.

The other motifs preferred in descending order were motif number 91(74.60), 19(73.50), 94(73.30), 10(72.70), 88(72.30), 60(70.26), 100(69.23), 24(68.10), 44(68.06) and 7(67.00) with XI, XII, XIII, XIV, XV, XVI, XVII, XVIII, XIX and XX ranks respectively out of collected 110 motifs. The least preferred motif was motif number 26 scoring 19.36 and ranked CX.

It is thus inferred that twenty top preferred motifs selected for development of designs for saris were motif number $97,89,66,73$, $70,93,65,12,95,110,91,19,94,10,88,60$, 100, 24, 44 and 7 (Plate-2).

\section{Simulation of Motifs into Designs}

This section includes simulation of selected motifs for the development of designs and selection of designs as per preferences of the experts.

\section{Design development}

All the selected Indian traditional motifs of appliqué (Plate-2) were critically analyzed and used as a source of inspiration for developing contemporary designs for saris. Designs were created using either one or combination of two to four motifs/ parts of motifs. Thirty seven designs were created using selected twenty motifs with the help of Corel DRAW software. Developed designs are shown in Plate -3 along with motif numbers used for development of particular design.

\section{Selection of designs}

All the developed thirty seven designs were visually evaluated by a panel of thirty experts and their preferential choices for created designs are depicted in Table 2.

The table shows that the most preferred design amongst developed designs was design number 19 developed by using motif number 93 only scoring highest mean score (31.30) and ranked I followed by design number 22 (30.16), a combination of motif number 89 and 93 ranked II, design number 24 (29.46) created by parts of motif number 97 and 88 ranked III, design number 5 (24.73) was developed using motif number 10 ranked IV and design number 23 ranked $\mathrm{V}$ with mean score 24.20 in which motifs number 110,7 , 88 and 19 were combined.

The preferences of experts for rest of the designs in descending pattern were design number 17(24.13), 6(24.10), 21(23.23), 31(23.06), 28(22.93), 34(22.76), 10(22.36), 36(22.30), 9(22.20), 3(21.90), 32(21.13), 8(20.93), 35(20.53), 14(20.33), 26(20.23), 2(19.83), 13(18.53), 16(18.16), 4(17.80), 1(16.56), 15(16.13), 29(15.90), 27(14.93), $7(14.20), \quad 18(14.06), 25(14.03), 33(12.26)$, 37(11.33), 30(10.10), 20(7.10), 11(5.93), and 12(5.00).

The design number 12 that scored 5.00 was least preferred design and ranked XXXVII. The data envisaged that the design number 19, 22, 24, 5 and 23 were five top ranked designs (Plate-4) which were selected as the best five selected motifs. 
Table.2 Preferential choices of designs $n=30$

\begin{tabular}{|c|c|c|}
\hline Designs No. & Mean scores & Ranks \\
\hline 1 & 16.56 & XIII \\
\hline 2 & 19.83 & XVII \\
\hline 3 & 21.90 & XXIII \\
\hline 4 & 17.80 & XIV \\
\hline 5 & 24.73 & IV \\
\hline 6 & 24.10 & XXXI \\
\hline 7 & 14.20 & VII \\
\hline 8 & 20.93 & XXI \\
\hline 9 & 22.20 & XXIV \\
\hline 10 & 22.36 & XXVI \\
\hline 11 & 5.93 & XXXVI \\
\hline 12 & 5.00 & XXXVII \\
\hline 13 & 18.53 & XVI \\
\hline 14 & 20.33 & XIX \\
\hline 15 & 16.13 & XII \\
\hline 16 & 18.16 & XV \\
\hline 17 & 24.13 & XXXII \\
\hline 18 & 14.06 & IX \\
\hline 19 & 31.30 & I \\
\hline 20 & 7.10 & XXXV \\
\hline 21 & 23.23 & $\mathbf{X X X}$ \\
\hline 22 & 30.16 & II \\
\hline 23 & 24.20 & $\mathbf{V}$ \\
\hline 24 & 29.46 & III \\
\hline 25 & 14.03 & VIII \\
\hline 26 & 20.23 & XVIII \\
\hline 27 & 14.93 & $\mathbf{X}$ \\
\hline 28 & 22.93 & XXVIII \\
\hline 29 & 15.90 & XI \\
\hline 30 & 10.10 & XXXIV \\
\hline 31 & 23.06 & XXIX \\
\hline 32 & 21.13 & XXII \\
\hline 33 & 12.26 & VI \\
\hline 34 & 22.76 & XXVII \\
\hline 35 & 20.53 & $\mathbf{X X}$ \\
\hline 36 & 22.30 & XXV \\
\hline 37 & 11.33 & XXXIII \\
\hline
\end{tabular}


Int.J.Curr.Microbiol.App.Sci (2020) 9(2): 2214-2227

Plate.2 Selected Motifs for Design Development

\begin{tabular}{|c|c|c|c|c|c|c|c|}
\hline $\begin{array}{c}\text { Motifs } \\
\text { No. }\end{array}$ & Motifs & $\begin{array}{l}\text { Mean } \\
\text { Scores }\end{array}$ & Ranks & $\begin{array}{c}\text { Motifs } \\
\text { No. }\end{array}$ & Motifs & $\begin{array}{c}\text { Mean } \\
\text { Scores }\end{array}$ & Ranks \\
\hline 7 & & 67.00 & XX & 73 & & 80.10 & IV \\
\hline 10 & & 72.70 & XIV & 88 & & 72.30 & XV \\
\hline 12 & & 78.00 & VIII & 89 & & 85.80 & II \\
\hline 19 & & 73.50 & XII & 9 & & 74.60 & XI \\
\hline 24 & & 68.10 & XVIII & 93 & & 79.00 & VI \\
\hline 44 & & 68.06 & XIX & 94 & & 73.30 & XIIII \\
\hline 60 & & 70.26 & XVI & 95 & & 77.90 & IX \\
\hline 65 & & 78.30 & VII & 97 & & 86.50 & I \\
\hline 66 & & 84.40 & III & 100 & & 69.23 & XVII \\
\hline 70 & & 79.60 & V & 110 & 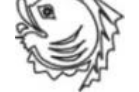 & 74.90 & X \\
\hline
\end{tabular}


Plate.3 Developed Designs using combinations of motifs

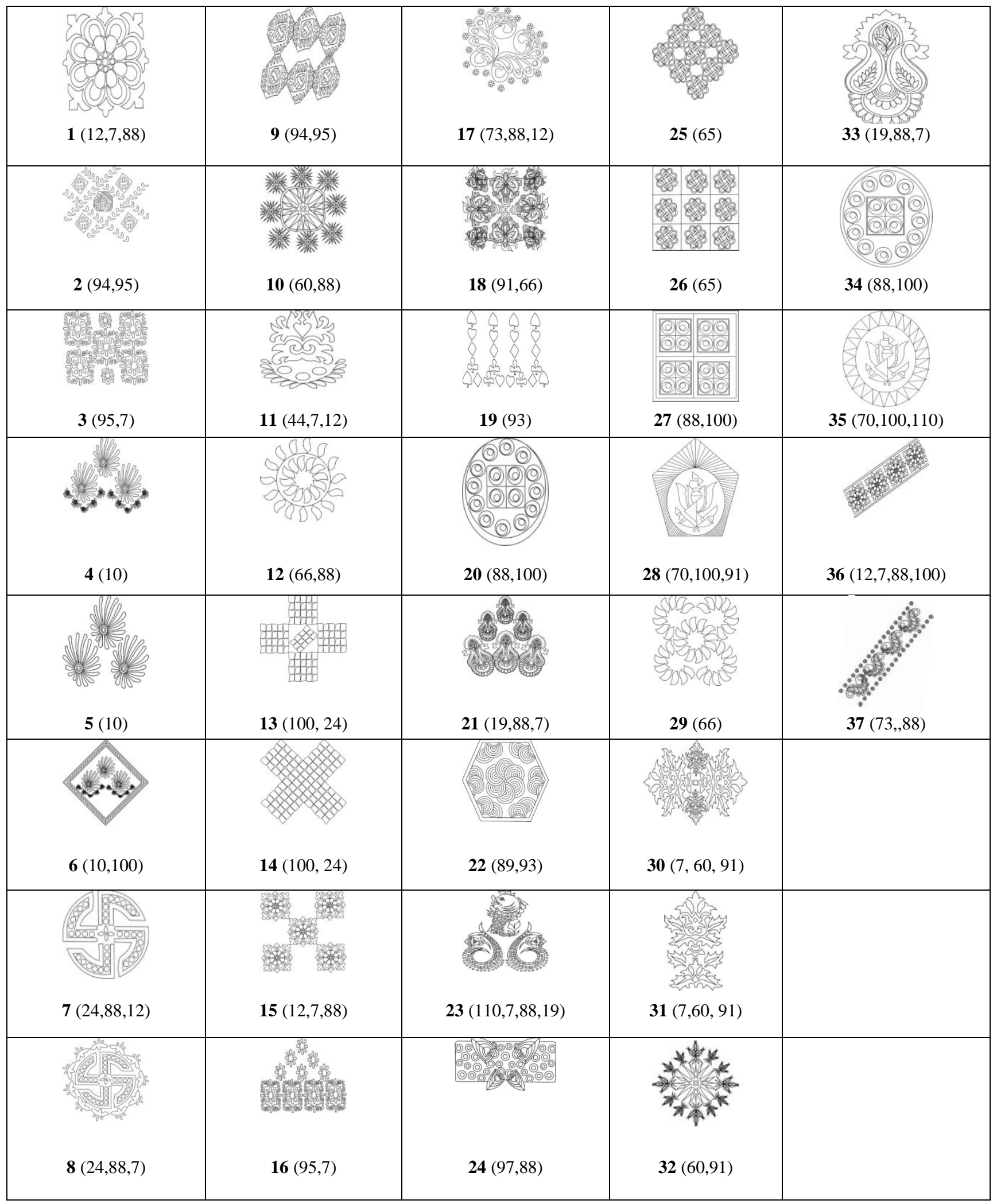


Plate.4 Selected top five designs

\begin{tabular}{|c|c|c|c|}
\hline Designs No. & Selected Designs & Mean Scores & Ranks \\
\hline 5 & & 24.73 & IV \\
\hline 19 & & 31.30 & I \\
\hline 22 & & 30.16 & II \\
\hline 23 & & 24.20 & V \\
\hline 24 & & 29.46 & III \\
\hline
\end{tabular}

Motifs play an important role in designing and each motif has its origin, evaluation and variety in shape and presentation. Traditional motifs can be described as the motifs which are being used in Indian textiles since ancient times and are handed over from one generation to the other. The 1000 traditional motifs were collected from primary and secondary sources and 110 motifs screened as per their suitability for appliqué on textile products.

Twenty motifs were selected from screened motifs as per the preferences of thirty experts. The twenty motifs were selected for design development. These motifs might have been preferred being appealing, exclusive and depicting the cultural heritage of India. The motifs and patterns provide significant elements for designing.
Designing is a rich play of elements and principles of design and creativity is alive by constantly experimenting with new media and designing techniques. Design simulation requires strong sense of imagination, creativity, use of elements and principles of designing. All the selected traditional motifs were assessed and each of the selected motifs was further manipulated or combined with other motifs using suitable designing software for developing innovative contemporary designs. Each developed design was creative because of use of traditional Indian motifs with unique arrangement and combination of selected motifs.

Thus, in the present scenario of fast life style, designs with assistance of CAD has not only expanded horizon of designing but also can create any number of designs that could be 
saved in the library to apply as and when required. $\mathrm{CAD}$ systems are more advantageous with respect to the speed, pattern creation, editing, repeating, flexibility, variety, colour ways and cost effective.

Computer in the hands of a designer can prove to be a tool of unlimited creativity with the system working as simple as an artist sketch book. The demonstrated benefits of CAD included increased productivity, reduced product development time, increased creativity to improve conceptual design, high product design capacity, reduced cost of sample and prototype.

\section{References}

1. Ariadnefabric. 2011. Textile glossary; Fabric, design terms, definitions used in textile design studios. Retrieved from www.arttowngifts.com on July 18, 2013.

2. Babel S, Tiwari $M$ and Dave J. 2013. Market potentials of Mewar wall paintings inspired sarees designs. Research J Management Sci, 2(5): 2427.

3. Banerjee A. 2012. Innovation is key to sustainable growth in Indian market. Home Fashion, India. 4(6):23.

4. Bhatnagar P. 2013. Traditional Indian textiles: The future in the world fashion. Retrieved from www.scribd. Dayalbagh Education Institute (deemed university) Dayalbagh, Agra.

5. Chattopadhyay KD. 2001. The glory of Indian handicrafts. $2^{\text {nd }}$ ed. Allied publications. New Delhi. Pp. 52.

6. Katiyar V. S. 2001. Innovation culture: design and technology interface economy. New Cloth Market. 35(2): 3944.

7. Kothari V R. 2011. Sublimation print: The future of printing. Indian. Text. J, 44(4): 56-58.
8. Mitra A. 2007. CAD/CAM: Ultimate solution for textile excellence. Indian Tex. J. 117 (12): 39-44.

9. Niaman R. 2001. Creativity in textiles: Indian market. Home Fashion, India. 2(4): 30-31.

10. Sethi RC and Sharma RB. 2011. CAD in the hands of the designer. Asian J Home Sci, 6(2): 292-294.

11. Shantanu and Nikhil. 2008. Style and sensibility. Retrieved from www. fibre2 fashion.com/article / 26/2540/gitting.asp on May 12, 2014.

15. Sharma E and Paul S. 2015. Adaptation of Indian folk paintings for designing and digital printing of apparels using computer added designing. International J Applied Res, 1(9): 989-995.

16. Srivastava M and Rajvanshi R. 2014. Developing colourways from Rajasthani miniature paintings using CAD technology. Asian J Home Sci, 9(1): 169-178.

17. Stout E E. 1994. Introduction to textile. $5^{\text {th }}$ ed. Macmillan publications, London. Pp. 307, 323.

18. Vaishnav S. 2015. Development of customized software on Warli folk art of Maharashtra for value addition. Ph.D. thesis, Maharana Pratap University of Agriculture and Technology, Udaipur, Rajasthan. Retrieved from www. valueaddition/pdf on December 112015.

19. Vasugi N and Kanimozhi M. 2011. Role of natural colourant in yarn dyeing. Colourage. 58(8): 80.

20. Vedika, Grover E and Paul S. 2014. Adaptation of Warli art for development of blocks for printing of apparels. Asian J Home Sci, 9(2): 417-421.

21. Wilson AJ. 2005. Handbook of textile design- Principles, process and practice. $3^{\text {rd }}$ ed. Woodhead Publications, Cambridge. Pp. 19-39. 


\section{How to cite this article:}

Ansul Sharma, Saroj S. J Singh, Neelam M Rose and Shefali Massey. 2020. Simulation of Applique Designs Using Cad. Int.J.Curr.Microbiol.App.Sci. 9(02): 2214-2227. doi: https://doi.org/10.20546/ijcmas.2020.902.250 